\title{
Subjetivação e Cura no Neopentecostalismo
}

Subjective and cure in the Neopentecostal

Subjetivación y cura en el Neopentecostalismo

Caio César Souza

Camargo Próchino

João Luiz Leitão Paradivini

Márcio Antônio Gonçalves

Universidade Federal de

Uberlândia

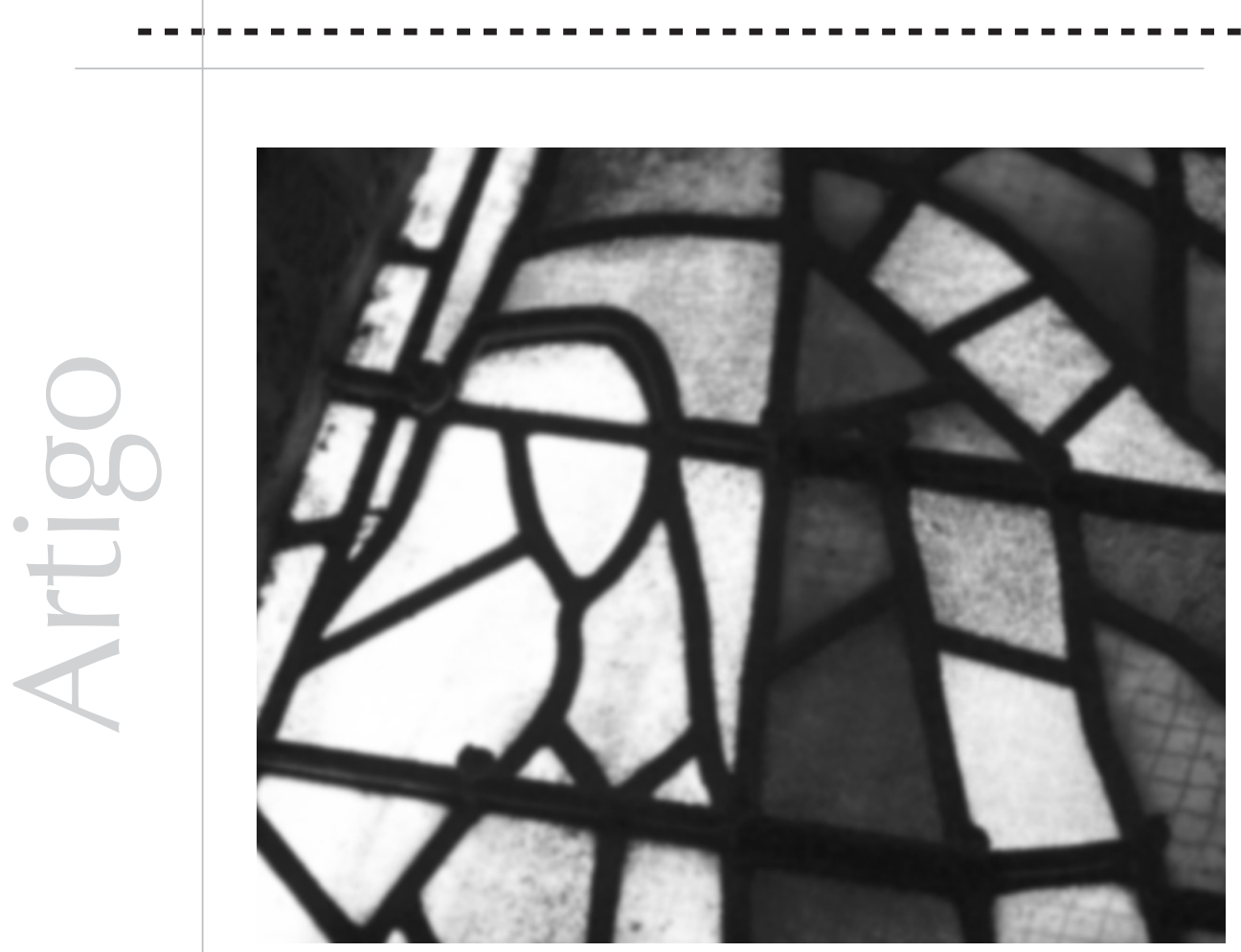


Resumo: Este artigo busca analisar algumas relações estabelecidas entre as transformações socioculturais ocorridas na contemporaneidade e a demanda de cura nas igrejas neopentecostais. A demanda de cura é apresentada como um dispositivo ou campo de força agenciador de processos ou modos de subjetivação. Os modos de subjetivação nas igrejas neopentecostais evidenciam a constituição do sujeito a partir de uma relação de causalidade direta entre os campos de flexão ou curvatura da fé e da ética. Se a demanda de cura é potencializada pela experiência da fé, por outro lado, os imperativos éticos moldam e limitam as condições para o processo de subjetivação do fiel. Não sendo possível a sustentação das promessas de cura veiculadas pelas igrejas neopentecostais dada a condição estrutural do desamparo humano, busca-se uma articulação possível entre a permanência da demanda de cura e a condição masoquista. O que se desvela nessa relação é o princípio da promessa sem cumprimento, ou seja, exatamente porque não se cumpre é que se sustenta uma posição subjetiva de sempre demandar.

Palavras-chave: Modos de subjetivação. Neopentecostalismo. Desamparo. Masoquismo.

\begin{abstract}
The purpose of this article is to analyze some relationships which have been established between contemporary socio-cultural transformations and the demand for cures in neo-Petencostal churches. The demand for cures appears to be a stratagem or a field force promoting processes or modes of subjectivity. The modes of subjectivity in the neo-Pentecostal churches give evidence to the constitution of the subject starting from a direct relationship of causality between the fields of the flexion or the curvature of faith and ethics. If, on the one hand, the demand for a cure is potential by the faith of experience, on the other hand, ethical imperatives mould and scan the conditions for the subjective processes of the believer. Since the neo-Pentecostal churches cannot sustain their promises of a cure, and given the structural condition of human helplessness, a possible articulation is procured between the permanence of the demand for cures and the masochistic condiction. What is revealed in this relationship is the principle of unfulfilled promises and it is exactly because the promises remain unfulfilled that the subjective position of ever demanding a cure is sustained.
\end{abstract}

Keywords: Modes of subjectivity. Neo-Petencostal. Human helplessness. Masochism.

Resumen: Este artículo busca analizar algunas relaciones establecidas entre las transformaciones socioculturales ocurridas en la contemporaneidad y la demanda de cura en las iglesias neopentecostales. La demanda de cura es presentada como un dispositivo o campo de fuerza proveedor de procesos o modos de subjetivación. Los modos de subjetivación en las iglesias neopentecostales evidencian la constitución del sujeto desde una relación de causalidad directa entre los campos de flexión o curvatura de la fe y de la ética. Si la demanda de cura es potenciada por la experiencia de la fe, por otro lado, los imperativos éticos moldean y limitan las condiciones para el proceso de subjetivación del fiel. No siendo posible la sustentación de las promesas de cura lanzadas por las iglesias neopentecostales dada la condición estructural del desamparo humano, se busca una articulación posible entre la permanencia de la demanda de cura y la condición masoquista. Lo qué se revela en esa relación es el principio de la promesa sin cumplimiento, o sea, exactamente porque no se cumple es que se sostiene una posición subjetiva de siempre demandar.

Palabras-clave: Modos de subjetivación. Neopentecostalismo. Desamparo. Masoquismo.

\title{
Subjetivação e cura no neopentecostalismo
}

Nós temos visto o grande sacrifício que as pessoas têm feito no afã de alcançarem as bênçãos de Deus. Muitas vezes, aplicam em suas vidas fórmulas que o mundo apresenta, e essa tem sido a razão por que o povo vem sofrendo os ataques do Diabo profundamente na carne, na alma e no espírito. (Edir Macedo)

A modernidade, através dos sólidos alicerces da racionalidade e da ciência, formulou a promessa de libertar o homem da submissão às experiências mágicas e religiosas que o infantilizavam. As luzes da razão prometeram um mundo dessacralizado e adulto.

O apagar das luzes da modernidade, na configuração de um novo modelo sociocultural, descrito por Lyotard como pós-modernidade, indicou o fracasso das chamadas grandes narrativas. Na pós-modernidade, acabaram 
os sistemas teóricos que buscavam dar conta da realidade inteira e que viabilizavam as explicações para todas as casuísticas articuladas em seu interior. O marxismo e o cristianismo são exemplos dessas grandes narrativas (Duarte, 1997).

No entanto, é em meio ao mundo marcado pelo rápido desenvolvimento científico e pelo permanente avanço tecnológico, que são pilares da consciência secular, que se pode evidenciar uma grande explosão da demanda religiosa até há pouco tempo relegada às sombras da ignorância pelos homens da luz. Surpreendentemente, o religioso que salta aos olhos da sociedade contemporânea é marcado por características expressivamente fundamentalistas.

Este artigo não pretende discutir a pertinência ou não do fim das grandes narrativas. $O$ estudo sobre as teorias da História parece ter essa questão como já equacionada.

O que aqui se pretende analisar é a relação que se pode estabelecer entre as transformações socioculturais da contemporaneidade, que sustentam novos modos de subjetivação, e as demandas de cura nas igrejas neopentecostais, que são operacionalizadas por uma ética pressuposta a partir das teologias do domínio e da prosperidade.

Uma primeira observação parece indicar que a demanda de cura põe em atividade um "campo de força" que é formador de novos modos de subjetivação.

A desqualificação do mundo profano, na afirmação da citação inicial deste artigo, como um mundo regido pelo Diabo também parece indicar que as religiões imaginam possuir as chaves para a abertura de uma nova realidade na qual o ser humano, finalmente, sob sua tutela, viveria sem as marcas do desamparo.
Na medida em que não existe cura para a condição estrutural do desamparo humano, o que implica a não sustentação das promessas religiosas de uma vida sem dor e sofrimento, a pergunta que se faz é sobre o que ainda vincula o sujeito a demandar pelo que não se pode ter e em nome de que a pertença se eterniza e a que ela está remetida.

Quando se observa, estrutural equalitativamente, as narrativas e as formas de relações processadas no interior das igrejas neopentecostais, deve-se também perguntar sobre o que se pode evidenciar e descrever, nesse universo religioso, como características de modos de subjetivação e de processos civilizatórios.

Finalmente, este artigo é perpassado pela preocupação de circunscrever o sujeito a partir de sua implicação sociohistórica. A pesquisa sobre os modos de subjetivação, que não dispensa a preocupação pelas regularidades do funcionamento psíquico do sujeito, aponta a necessidade de se promover a sua inscrição numa ordem de espaço e tempo socioculturais.

Uma preocupação deste estudo, ao privilegiar um viés interpretativo para a contextualização sociocultural, é a de indicar que o Brasil está cortado por várias temporalidades. Ainda se pode falar de um Brasil colonial que vive sob o registro do trabalho escravo, o qual convive contraditoriamente com um Brasil hipermoderno, marcado pelo signo da individualidade autônoma exacerbada.

\section{Modos de subjetivação e neopentecostalismo: uma articulação possível}

Uma indagação inicial que deve ser feita destaca a possibilidade de se promover uma articulação entre a subjetividade e o dado social. O interesse é o de se romper com uma certa perspectiva psicanalítica que evidencia o sujeito somente a partir de suas 
"O humanismo cartesiano, radicado no

homem enquanto racionalidade, não terá passado por cima de outras dimensões humanas

fundamentais, como, por exemplo, as exigências do coração e,

ousaria dizer, do estômago?"

(Lara, 1988) características intrapsíquicas - inconscientes - que acaba quase por sustentar uma concepção essencialista do ser humano. É nessa direção que Birman (2005) ressalta o desafio de ordem metodológica que é posto à psicanálise. Diz ele:

Durante muito tempo, a psicanálise se habituou a responder aos problemas sociais e políticos de maneira naturalista, isto é, como se determinadas características e traços presentes no psiquismo humano fossem os responsáveis diretos por certas formas de práticas sociais. Assim, a ordem social e suas práticas seriam as conseqüências imediatas de certas marcas universais do espírito humano. Portanto, o modelo explicativo e causal em pauta seria não apenas naturalista mas também determinista. (p. 294)

A identificação do indivíduo como um ser social tornou-se uma compreensão comum entre os diversos campos de conhecimento das ciências humanas. No entanto, a análise da epistemologia subjacente a essa compreensão mostra a existência de uma oposição entre a idéia de um sujeito, circunscrito ao campo da interioridade, e o social como aquilo que lhe é externo. Essa dicotomia entre interno / externo está remetida às raízes da Filosofia moderna, especificamente à influência da definição do sujeito a partir de Descartes. Ao estabelecer uma dicotomia entre res cogitans (substância espiritual/ pensamento) e res extensa (substância material), Descartes promove, nos primeiros passos da modernidade, a inauguração e a constituição de uma filosofia racionalista. Nesse sentido, Lara (1988) faz uma significativa observação sobre o humanismo cartesiano. Em suas palavras: "O humanismo cartesiano, radicado no homem enquanto racionalidade, não terá passado por cima de outras dimensões humanas fundamentais, como, por exemplo, as exigências do coração e, ousaria dizer, do estômago?" (p. 39).
A Psicologia também foi tributária dessa mentalidade que estabelece uma dicotomia da realidade humana pelos pólos da exterioridade e da interioridade. Quando a Psicologia dava seus primeiros passos, Wundt considerava a consciência como seu objeto de estudo. Aqui, a consciência era entendida como uma realidade remetida ao campo da interioridade, e o seu acesso só era possível através da introspecção. É nesse enquadramento sociocultural que se pode ver o nascimento da Psicologia como uma ciência autônoma e separada das ciências que tomavam o social como fenômeno de estudo.

É ao longo do último século que se pode observar o nascimento de uma nova perspectiva de compreensão que estabelece uma relação fundamental entre a subjetividade e os campos da sociabilidade humana. A idéia é estabelecer uma relação entre o social e a subjetividade que não seja marcada pela lógica da causalidade.

Ferreira Neto, apoiado nas formulações de Deleuze e Guattari, indica uma nova possibilidade de compreensão da subjetividade que deve ser precisada a partir da lógica da inscrição histórica e da emergência de implicação de vários processos. Eis a compreensão de subjetividade por ele sustentada:

É outra a concepção de subjetividade que gostaria de abordar aqui. A subjetividade, entendida como emergência histórica de processos não determinados pelo social, mas em conexão com os processos sociais, culturais, econômicos, tecnológicos, midiáticos, ecológicos, urbanos, que participam de sua constituição e de seu funcionamento. (Ferreira Neto, 2004, p. 4)

Nessa perspectiva, a subjetividade deixa de ser entendida como estrutura, que remete à noção de interioridade identitária, e passa a ser compreendida como processo. A lógica 
dos processos ou modos de subjetivação pressupõe uma permanente transformação na medida em que se deve sempre contextualizar os sujeitos nos campos de força ou fluxos de implicações intersubjetivas no mundo em que vivem.

Michel Foucault é um pensador que trabalha com esse modelo interpretativo. Em seus estudos, pode-se observar a preocupação com uma genealogia do sujeito de desejo na modernidade. A noção de sujeito de desejo em nada se casa com a idéia da definição do ser humano a partir de uma estrutura essencial. O que transparece é a compreensão de um modo de subjetivação numa inscrição sciohistórica determinada. Ao analisar a formação e o desenvolvimento da experiência da sexualidade a partir do século XVIII, Foucault (1984) deixa claro que seu interesse não é o de estabelecer uma história das concepções do desejo, da concupiscência ou da libido, mas, ao contrário, o de promover uma análise das práticas pelas quais os indivíduos foram levados a se decifrar e a se reconhecer como sujeitos de desejo.

Desse modo, apoiando-se em Foucault, é que se pode dar sustentabilidade a um sujeito envolvido historicamente. A subjetividade, nessa perspectiva, passa a ser implicada nos processos históricos, sociais, políticos, econômicos e culturais. Aqui é afirmada a possibilidade da superação de uma compreensão naturalista da subjetividade.

O esforço na busca da inscrição sociohistórica da constituição da subjetividade humana pode ser remetido à contribuição de Deuleze no que se refere ao conceito de "dobra". Para Neves da Silva (2004), o conceito de "dobra exprime tanto um território subjetivo quanto o processo de produção desse território, ou seja, ela exprime o próprio caráter coextensivo do dentro e do fora" (p. 2). Assim, é à luz dessa idéia que se podem compreender os processos ou modos de subjetivação. $\mathrm{O}$ processo de subjetivação diz respeito à flexão ou curvatura sustentada por certas relações de forças. Nesse sentido, os diversos momentos históricos de nossos processos civilizatórios podem ser analisados a partir das dobras ou curvaturas que desvelam relações de forças formadoras de características particulares. A idéia de dobra como um operador conceitual evidencia os diferentes modos de subjetivação ao longo da História.

Para Deleuze (1986), a subjetivação se faz por dobra, e existem quatro tipos de dobras que estão presentes em qualquer modo de subjetivação. Na primeira dobra, evidenciase a parte material do sujeito e que, cercada, é também presa na dobra. Trata-se, para os gregos, do corpo e dos seus prazeres, os aphrodisia; para os cristãos, trata-se da carne e de seus desejos. A segunda dobra é constituída pela relação de forças no seu sentido mais exato. É segundo uma regra singular que a relação de forças é vergada para se tornar uma relação consigo (pode ser natural, divina, racional ou estética...). A terceira dobra pode ser caracterizada como a dobra do saber ou da verdade, e constitui uma ligação da verdade com o nosso ser e do nosso ser com a verdade. A subjetivação do saber toma formas diferentes ao longo da História. A quarta dobra se constitui no próprio lado de fora. É dessa dobra que o sujeito espera, de vários modos, a imortalidade, ou a eternidade, a salvação, a liberdade... Ainda, segundo o próprio Deleuze (1986):

Essas dobras são eminentemente variáveis,
aliás, em ritmos diferentes, e suas
variações constituem modos irredutíveis de
subjetivação. Elas operam "por sob os códigos
e regras" do saber e do poder, arriscando-
se a juntar-se a eles se desdobrando, mas
não sem que outras dobraduras se façam.
(p. 112) Essas quatro dobras caracterizam um modo de subjetivação específico que é designado 
A partir do final da década de 70, com o objetivo de evidenciar a superação das características da sociedade moderna bem como de salientar a nova configuração das sociedades desenvolvidas, surgiu o conceito de pósmodernidade

(Duarte, 1997, p. 32). por Guatarri de capitalístico. Esse modo de subjetivação diz respeito à realidade das sociedades contemporâneas tanto capitalistas quanto socialistas, na medida em que ambas vivem em uma relação de dependência e de contra-dependência do modelo capitalista (Neves da Silva, 2004, p. 14).

A partir do final da década de 70, com o objetivo de evidenciar a superação das características da sociedade moderna bem como de salientar a nova configuração das sociedades desenvolvidas, surgiu o conceito de pós-modernidade (Duarte, 1997, p. 32).

Para muitos teóricos, o fim das metanarrativas, a fragmentação dos alicerces da racionalidade, a dinâmica de individualização, a pluralização das sociedades, a consagração de uma temporalidade social baseada no presente, a privatização da família e da religião e a onipresença do mercado são algumas das características da sociedade pós-moderna.

Lipovetsky (2004) sustenta que a sociedade dita pós-moderna sequer existiu. Ele afirma que

...o pós de pós - moderno ainda dirigia o olhar para um passado que se declarava morto; fazia pensar numa extinção sem determinar o que nos tornávamos, como se se tratasse de preservar uma liberdade nova, conquistada no rastro da dissolução dos enquadramentos sociais, políticos e ideológicos. (p. 53)

O conceito de hipermodernidade evoca a compreensão das sociedades atuais que, em seu enquadramento estrutural e funcional, são elevadas à potência superlativa. Trata-se de evidenciar as dinâmicas de funcionamento subjetivo e intersubjetivo sob o crivo do excesso.

Para Lipovetsky, na hipermodernidade, não existe uma força estruturante de oposição à modernidade democrática, liberal e individualista. Os fracassos das experiências socialistas, sobretudo no Leste Europeu, parecem ter fortalecido a ideologia hegemônica do mercado globalizado.

Outra característica da hipermodernidade diz respeito ao princípio da individualidade autônoma. A constituição de uma cultura individualista indica a fragmentação das sociedades, que se estruturavam a partir dos modelos de classes sociais e cultura de classe. Pode-se, cada vez mais, notar a destituição dos laços sociais para a legitimação de uma lógica que aprisiona o sujeito em seu próprio umbigo. Os comportamentos individuais são vividos sob o signo do extremo.

De uma sociedade marcada pela dinâmica do engajamento e da filiação político-partidária, passa-se agora à cultura da festa. Lipovetsky descreve o funcionamento individual em uma esfera de uma cultura apolítica. Podese apostar em um hiperindividualismo paradoxal. Como exemplo, pode-se falar da cultura do corpo. Se, por um lado, as pessoas cuidam obsessivamente do corpo, se mostram fanáticas por higiene e saúde, por outro, proliferam as patologias individuais, como a bulimia e a anorexia.

No contexto da economia mundial, evidenciase a destituição da autonomia administrativa dos governos e a redução da participação da sociedade na definição das prioridades sociais. O mercado descreve os sacrifícios necessários para a consolidação das políticas de metas que incluem os Estados que desejam se sustentar na economia globalizada.

Outra característica das sociedades hipermodernas é a eficiência da tecnologia e as transformações operadas nos referenciais sobre a vida humana.

Para Lipovetsky, a hipermodernidade não aboliu em definitivo os apelos às tradições de sentido sagrado. A seu ver, o que se pode observar é um rearranjo pela mediação da 
individualização, dispersão e emocionalização das crenças e práticas. Em suas palavras:

...o avanço da secularização não leva a um mundo inteiramente racional em que a influência social da religião declina continuamente. A secularização não é só a irreligião; ela é também o que recompõe o religioso no mundo da autonomia terrena, um religioso desinstitucionalizado, subjetivo e afetivo. (Lipovetsky, 2004, p. 94)

Se, nas sociedades tradicionais, a identidade religiosa e cultural era articulada como algo natural, nas sociedades desenvolvidas, evidencia-se como uma demanda reivindicatória, como objeto de apropriação dos indivíduos.

A identidade religiosa do neopentecostalismo pode ser circunscrita nesse universo. A demanda religiosa neopentecostal tem sido evidenciada como uma das que mais crescem na realidade do pluralismo religioso contemporâneo da sociedade brasileira. Não são poucos os que já falam da instauração da lógica de um mercado religioso, que lança suas garras na disputa por aqueles que vêem nas promessas religiosas a única possibilidade de salvação para um mundo desencantado. Freston, a partir do corte histórico-institucional e da análise da dinâmica interna do pentecostalismo, foi o primeiro a dividir o movimento pentecostal no Brasil utilizando a metáfora de três ondas. Para ele,

O pentecostalismo brasileiro pode ser compreendido como a história de três ondas de implantação de igrejas. A primeira onda é a década de 1910, com a chegada da Congregação Cristã (1910) e da Assembléia de Deus (1911). ...A segunda onda pentecostal é dos anos 50 e início de 60, na qual o campo pentecostal se fragmenta, a relação com a sociedade se dinamiza e três grandes grupos (em meio a dezenas de menores) surgem: a Quadrangular (1915), Brasil para Cristo (1955) e Deus é Amor (1962)... A terceira onda começa no final dos anos 70 e ganha força nos anos 80 . Seus principais representantes são a Igreja
Universal do Reino de Deus (1977) e a Igreja Internacional da Graça de Deus (1980)... . (Freston, citado por Mariano, 2005, p. 28)

A terceira onda é designada de neopentecostalismo. Ela começa na segunda metade dos anos 70 e ganha corpo e se fortalece nos anos 80 e 90 . Os pesquisadores brasileiros já consagraram o termo neopentecostalismo no estudo dos fenômenos que circunscrevem as denominações religiosas daqueles que estão inscritos nessa terceira onda.

Mariano (2005), num estudo realizado sobre a sociologia do novo pentecostalismo brasileiro, ressalta três características fundamentais que têm a força de traduzir e identificar as igrejas neopentecostais, a saber: a exacerbação da guerra espiritual contra o Diabo e seu séqüito de anjos decaídos, a pregação da Teologia da Prosperidade e a liberalização dos estereotipados usos e costumes de santidade. Ele ainda resgata como uma quarta característica, que é descrita por Oro, o fato de essas igrejas se estruturarem empresarialmente.

Os rituais de exorcismo nas igrejas neopentecostais, sobretudo na Igreja Universal do Reino de Deus, põem em evidência a figura do Diabo, que é identificado com as entidades das religiões afro-brasileiras. Os rituais ganham ares de espetáculo, e o objetivo é dobrar até ao chão as forças que buscam escravizar a vida humana. O exorcismo pontualmente faz refletir sobre a idéia de uma guerra espiritual entre Deus e o Diabo pelo domínio do mundo. A Teologia do Domínio desvela um universo de batalhas espirituais contra demônios que estão instalados na vida das pessoas e que, acredita-se, têm a força de promover verdadeiras destruições nas diversas dimensões da existência humana. De acordo com o que pode ser freqüentemente assistido nos programas religiosos veiculados pela televisão, os demônios se ocupam da vida da pessoa por ela viver de forma 
contrária às exigências bíblicas, por meio de "despachos" promovidos por adversários ou por laços hereditários. Nesse universo, somente o poder de Deus pode libertar a vida do fiel. É à liderança religiosa que é conferido ou outorgado o poder de promover a libertação espiritual na vida daqueles que foram dominados pelas forças malignas do demônio.

A Teologia da Prosperidade nasceu nos Estados Unidos, na década de 40, mas é somente a partir dos anos de 1970 que se constitui em um movimento doutrinário. Essa teologia está fortemente ligada ao fenômeno do televangelismo americano, e, no Brasil, constitui uma característica fundamental do neopentecostalismo.

De acordo com essa teologia, o desejo de Deus é que todos os seus filhos desfrutem de todos os benefícios para uma vida feliz na terra. Saragoça (2004) afirma que:

...de acordo com essa teologia, o fiel só não será recompensado com dádivas se não tiver fé suficiente. Segundo essa orientação, deve-se exigir de Deus o que é seu por direito. É preciso querer e crer que aquilo que se busca é possível, e deve-se ainda agradecer antecipadamente, o que será uma demonstração de fé, de crença de que o "pedido" já foi respondido. (p. 37)

Assim, a Teologia da Prosperidade sustenta a crença de que o fiel está destinado a ser próspero, saudável e feliz já neste mundo. Dá-se, aqui, um rompimento com a idéia da busca da salvação pelo ascetismo de rejeição do mundo. Assim, o crente deve promover uma afirmação do mundo que lhe possibilite o gozo do dinheiro e do status social. Diz Mariano:

O apego dos neopentecostais ao mundo é indisfarçável. Em contraste, sobretudo, com o pentecostalismo clássico, que enfatiza a salvação celestial e exorta constantemente o fiel a permanecer firme na fé diante da proximidade do Juízo Final, a preocupação primordial que transparece na mensagem neopentecostal é com esta vida e com este mundo. O que interessa é o aqui e o agora. $\mathrm{E}$, para isso, nada melhor do que ter Cristo no coração, meio infalível de alcançar a vitória sobre o Diabo e obter a retribuição divina agora e sempre. (p. 44)

Ao fiel, não se exige somente uma fé inabalável e uma disponibilidade irrestrita para a vivência das regras bíblicas para que possa obter as infinitas bênçãos divinas; dele também se exige um sacrifício de ordem financeira. Ele deve ser fiel nos dízimos e deve fazer ofertas generosas em nome de sua fé e do seu amor.

Assim, a Teologia do Domínio e a Teologia da Prosperidade promovem no neopentecostalismo um distanciamento com a escatologia pentecostal clássica que leva a uma auto-exclusão da vida social e a um ascetismo intramundano.

As igrejas neopentecostais rompem também com uma perspectiva legalista que rege o pentecostalismo e pela qual o fiel, na busca do estado de santidade, se distingue por sua aparência. A distinção se processa e é simbolizada por uma identidade que é negadora de vaidades, prazeres e modismos mundanos. As igrejas Renascer em Cristo e a Comunidade Evangélica Sara nossa Terra são exemplos de experiências neopentecostais que subvertem esse princípio. Nessas denominações religiosas, a moda é uma experiência posta ao serviço da evangelização.

O neopentecostalismo pode, ainda, ser analisado por se estruturar empresarialmente. A revista Veja publicou uma matéria intitulada "Os Novos Pastores", na qual se destaca que a qualificação dos novos pregadores não vem ao encontro somente da modernização do discurso, mas objetiva também aprimorar as técnicas de gerenciamento das igrejas (Pereira \& Linhares, 2006, p. 83). A disputa pelas 
concessões das diversas mídias, a inserção no universo do marketing, o gerenciamento de grandes conglomerados imobiliários, de uma extensa população de servidores voluntários e contratados, sob o regime da CLT, têm exigido cada vez mais profissionais habilitados na administração de recursos humanos e empresariais.

\section{Cura e políticas de subjetivação}

A origem dos males causadores das diversas formas de sofrimento humano, na perspectiva de compreensão neopentecostal, está radicada na ação do Diabo, que se serve da abertura que as pessoas a ele oferecem por seus estilos de vida contrários às exigências da Bíblia Sagrada. Marinho (2001) assim afirma:

Nosso adversário, em primeiríssimo lugar, é o Diabo. Mas, na realidade, temos mais de um adversário. Enfrentamos batalhas, também, contra outros adversários, que são o mundo, o pecado e a carne... O Diabo tem uma maneira de lidar com os incrédulos e outra maneira de lidar com os crentes. Para os incrédulos, ele diz: "Esse negócio de Deus é bobagem. Deus não existe!". Já os crentes, ele os faz lembrar dos sofrimentos pelos quais estão passando, e coloca em dúvida se Deus está vendo ou não esse sofrimento. (pp. 27-28)

Pode-se, assim, compreender que a lógica interpretativa sustentada pelas igrejas neopentecostais conduz a uma explicação na qual as formas de organização das sociedades têm sido marcadas pela regência das ações e influências do Diabo, que parece sempre vencer as batalhas quando não é barrado pela interdição de Deus e da fé do crente.

Ademais, uma explicação dessa natureza acaba também por sustentar que as saídas da submissão ao mundo, ao pecado e à carne só são possíveis quando se aposta nos recursos espirituais. Para Marinho (2001),

\begin{abstract}
Assim, na batalha espiritual, se os recursos são humanos, eles fracassam; ainda que bem sucedidos em alguns aspectos visíveis, os resultados de uma vitória puramente humana não trazem o benefício que seria atingido se lutássemos com as armas espirituais. (p. 28)
\end{abstract}

Nesse contexto, também pode ser inserida a compreensão de Macedo (2005). Em suas palavras:

Então temos a absoluta certeza de que todos os problemas que o ser humano enfrenta estão ligados diretamente ao campo espiritual e, sendo assim, não há outra maneira pela qual possamos lutar e vencer senão através da fé em nome do Senhor Jesus Cristo. (p. 24)

A crítica às sociedades contemporâneas desenvolvidas, feita pelas igrejas neopentecostais como sociedades sem Deus e, por isso, marcadas pelas diversas formas de sofrimento, indicam que haveria a possibilidade da constituição de um novo processo civilizatório capaz de instaurar o reino da pura felicidade sobre a Terra. Nesse reino, todos os problemas e todas as formas de sofrimento seriam extirpados do ser humano. Assim diz Braga de Almeida (1996):

Se os médicos não têm a cura da AIDS, quando o homossexualismo, a prostituição e todos os desvios de conduta são problemas para a sociedade, quando não há como contê-los, quando os nossos recursos acabam, é hora de pedirmos uma intervenção celeste. É hora de deixarmos Deus agir. Ele, sim, pode resolver os problemas da humanidade. Basta deixarmos o Deus do impossível agir. Ele cura, liberta, transforma e recupera VIDAS. A Bíblia diz que Ele é o mesmo ontem, hoje e eternamente. Isso quer dizer que ele curava, libertava, cura e liberta hoje, e estará sempre disposto a fazer de nós pessoas saudáveis. (p. 84)

Nessa perspectiva, o dispositivo da cura pode ser tomado como um campo de força que constitui elemento agenciador de processo ou modo de subjetivação. Aqui, interessa desvelar a flexão ou curvatura que deflagra o 
Diz Macedo (2000):

O dinheiro é uma ferramenta sagrada na obra de Deus. Ele é o dono de todas as coisas, mas nós somos os sócios nos Seus empreendimentos. Dessa maneira, o dinheiro, que

é humano, deve ser a nossa participação, enquanto o poder espiritual e os milagres, que são divinos, são a participação de Deus. (p. 52) modo de subjetivação que é inaugurado pelas lógicas das igrejas neopentecostais. Esse modo de subjetivação parece forjar a constituição do sujeito a partir da vertente da fé e da ética. O dispositivo da cura é potencializado pela experiência da fé e fundamentado pelo imperativo da ética. A ética, por sua vez, delimita, molda e enquadra as condições para o processo de subjetivação do fiel.

O dispositivo da cura é aqui entendido como a realização - atualização - de uma promessa divina. A cura remete à idéia de uma transformação da existência do fiel na superação de todas as suas formas de sofrimento e em meio a todos os contextos vitais nos quais se encontra. Assim diz Macedo (2000) sobre uma vida de abundância:

A vida abundante que Deus, pelo Seu grande amor, nos garante através de Jesus Cristo inclui todas as bênçãos e provisões de que necessitamos, ou mesmo que venhamos a desejar. ...Deus nos reserva o direito de serem preenchidos em nós os três aspectos da vida humana que podem fazêla feliz: espiritual, físico e financeiro. (p. 27)

Para Macedo (2000), a promessa divina de uma vida abundante pressupõe a cura das enfermidades do corpo, porque a felicidade se torna impossível na vida de uma pessoa que é tomada pela doença e também porque Deus não se descuidaria dessa parte em relação a seus filhos. Em sua compreensão, o crente deve concordar com a palavra de Deus e confessar sua vitória sobre as doenças.

Macedo diz que existem cinco razões pelas quais se pode ter certeza da cura, a saber: Deus promete curar, Jesus Cristo curava os doentes, Jesus Cristo mandou seus discípulos curarem os enfermos, os milagres de cura se manifestavam em todo lugar no ministério da igreja e Jesus comissionou todos os que crêem, de todas as nações, para curar os enfermos.
Nessa mesma lógica de compreensão, o dinheiro é também uma ferramenta sagrada utilizada por Deus no processo de transformação da vida dos fiéis. Diz Macedo (2000):

O dinheiro é uma ferramenta sagrada na obra de Deus. Ele é o dono de todas as coisas, mas nós somos os sócios nos Seus empreendimentos. Dessa maneira, o dinheiro, que é humano, deve ser a nossa participação, enquanto o poder espiritual e os milagres, que são divinos, são a participação de Deus. (p. 52)

O apelo que é feito para a operacionalização da abundância de bênçãos na vida financeira diz respeito à obediência à palavra de Deus. Segundo Macedo (2000), para a edificação de uma vida próspera, o fiel deve obedecer à palavra de Deus, e, se Deus manda dar o dízimo, deve-se fazer isso e esperar a resposta. Ao crente que testemunha a fidelidade no contrato ou na sociedade divina, só restará ser abençoado, posto que a Deus apenas caberá honrar suas promessas de bênçãos.

Desse modo, a cura constitui um dispositivo agenciador ou um campo de força que promove a entrada em um novo processo de subjetivação. A demanda de cura, nesse contexto, pode ser considerada em sua relação direta com os modos de subjetivação que são forjados e sustentados pelas igrejas neopentecostais.

A relação aqui estabelecida entre demanda de cura e modos de subjetivação desemboca numa questão antropológica, a saber: que sujeito é esse que pode ser desvelado nesse processo de subjetivação das igrejas neopentecostais e em nome de que ele ainda potencializa demanda mesmo quando não usufrui das promessas religiosas de uma vida em abundância?

Uma consideração inicial sobre o sujeito que entra no universo religioso neopentecostal 
é que dele se espera que tenha fé. Por fé, entende-se a certeza e a confiança de que Deus irá cumprir todas as suas promessas, que estão contidas nas Escrituras Sagradas. É esse o entendimento de Macedo (2005):

Em outras palavras, fé é a certeza que temos dentro de nós de que Deus cumprirá todas as Suas promessas escritas nas Sagradas Escrituras. Muitas pessoas incrédulas afirmam: "Eu preciso ver para depois crer"; entretanto, a fé é exatamente o contrário do que o Diabo ensina, isto é: primeiramente, nós cremos de todo o nosso coração, para então podermos ver com os nossos olhos físicos. (p. 17)

Ao sujeito que vive sob a regência da fé, também se impõe a condição de que ele promova mudanças em sua vida que tenham a força de traduzir a sua saída da submissão ao mundo marcado pelas seduções do Diabo. A fé teria a força de produzir as transformações onde o ser humano não consegue chegar confiando exclusivamente em si mesmo. Para Macedo (2005),

A fé é tudo isso e mais ainda, desde que focalizada no Deus Vivo. Ela transforma o ambiente, qualquer que seja ele, e, por mais tenso e tenebroso que possa parecer, a fé o limpa e o purifica; o que os médicos não podem fazer, o que os remédios não podem realizar, a fé faz e realiza. Ela torna possíveis todos os impossíveis da vida, transcendendo até mesmo a própria razão. (p. 16)

Macedo (2005), considera que a fé pode ser ainda entendida como uma parte de Deus presente no crente. Na medida em que o sujeito põe a fé em evidência, ele se torna ilimitado naquilo que deseja realizar, pois, vivendo de acordo com a vontade de Deus, o próprio Deus se torna seu sócio na realização do que busca.

No entanto, a parceria ou sociedade divina pressupõe um preço a ser pago. É sustentando essa idéia que Macedo faz a seguinte afirmação: "Tudo que é valioso tem um preço. Para conseguir a medida suficiente de fé a ponto de transportar montanhas, também devemos esperar o preço que precisamos pagar por isso" (Macedo, 2005, p. 24). Em sua compreensão, ao sujeito que deseja uma fé vitoriosa, caberá como exigência que se esvazie de si mesmo, que leia a Bíblia, para que, nela, pelo Espírito Santo, encontre a verdade e seja obediente a Deus.

Assim, pode-se considerar que, se o sujeito sustenta sua demanda de cura em nome da fé, também fica evidente uma implicação do campo da ética como condição de exigência subjetiva. Ao sujeito que diz acreditar nas promessas divinas e merecer usufruir de todas as bênçãos, restaria ainda o desafio de agir em conformidade com essa fé. A lógica que aqui se instaura é a de uma relação direta entre fé e ética. O mapeamento do universo subjetivo e das relações intersubjetivas é, assim, margeado e enquadrado à luz das exigências bíblicas e daquilo que é considerado como verdade nas construções de sentido das lógicas explicativas neopentecostais.

Segundo Soares (2004), para se tornar um vencedor, é necessário passar por uma mudança radical de vida, é preciso nascer de novo.

Na lógica das explicações neopentecostais, esse novo nascimento pressupõe o ajustamento do sujeito às exigências da Sagrada Escritura.

É nesse universo que podem ser evidenciados os discursos quanto ao pecado da homossexualidade e é onde também se percebe a formalização de uma métrica dos comportamentos compatíveis com a vida dos que renasceram em sua fé.

A demanda de cura que é alimentada e posta em movimento pela dinâmica da fé promove também o enlaçamento do sujeito que é 
margeado ou balizado a partir da instância da ética. Aqui o sujeito é permanentemente chamado a responder ao outro, no plano dos comportamentos e da constituição de uma identidade estável e fixa, pela lógica do assujeitamento. Esse sujeito é capturado e regido pela lógica de um outro institucional que em tudo se faz prometer.

Assim sendo, pode-se considerar a relação dos modos de subjetivação gestados no interior das igrejas neopentecostais e a condição fundamental do desamparo humano.

\section{Neopentecostalismo, desamparo e condição masoquista}

O desamparo é marca que possui uma força expressiva de tradução dos modos de subjetivação na contemporaneidade.

Num primeiro plano, aponta o declínio da razão universal e do projeto iluminista que predominaram durante a modernidade e reivindicaram a possibilidade de trazer a emancipação humana para além do universo das crenças. De fato, seus ideais de evolução e transformação ruíram com o declínio da modernidade.

Para Forbes (2004), a queda dos alicerces que sustentaram o projeto iluminista e a razão universal durante a modernidade trouxe como conseqüência o declínio dos valores da sociedade tradicional e resultou em uma ausência da figura simbólica do pai na cultura. Em sua visão, no cerne desse processo, podese compreender o surgimento do sentimento de desproteção e o enfraquecimento dos laços sociais.

Diante da nova configuração sociocultural da contemporaneidade, o problema evidenciado não é tanto o desamparo ou a fragilidade imanente à condição humana, mas sim, os destinos dados pelo sujeito à sua condição de desamparo. Diz Forbes (2004):
...A questão relevante é procurar saber que destinos o sujeito consegue dar para sua condição de desamparo, uma vez que esta tanto permite ao sujeito uma liberdade de ser, de criar seu mundo singular, quanto pode conduzir a formas alienantes de subjetividade. (p. 73)

Assim, um problema que se coloca é saber de que modo o desamparo na sociedade hipermoderna se articula com as transformações ocorridas nas últimas décadas, sobretudo tendo o olhar voltado para o fenômeno do neopentecostalismo.

As saídas da experiência de desamparo construídas na contemporaneidade parecem apostar nas vias do imaginário em detrimento das possibilidades simbólicas. Aqui, a evidência é conferida a um eu inflado, com as características de um narcisismo patológico.

Outro investimento possível frente ao desamparo na ordem cultural se dá pela posição masoquista. Esse parece ser o campo construído nas relações processadas no interior das igrejas neopentecostais.

Diferentemente dos masoquismos feminino e moral, que integram o que recebe em Freud a designação de masoquismo secundário, no masoquismo erógeno, o desamparo não é marca de característica negativa, porquanto desvela o que é identidade estrutural humana. No masoquismo erógeno, o sujeito acolhe sua fragilidade não como aquilo de que se deve escapar, mas sua fragilidade é o que permite sua vinculação subjetiva na ordem do desejo, sua implicação com as demandas da vida.

Ao contrário, no masoquismo feminino e moral, o que importa, mais que a associação do prazer com a dor, é uma posição de assujeitamento ao outro como possibilidade de saída do desamparo. Aqui, o sujeito não é 
De acordo com Birman (2005), podem-se compreender os processos de reevangelização que são

empreendidos pelas religiões no mundo

contemporâneo como movimentos de busca de proteção contra o desamparo. vítima da situação, posto que o que nela se busca é a ilusão de proteção que se alcança na relação com uma figura tirânica.

Os modos de subjetivação presentes nas igrejas neopentecostais parecem mostrar essa forma do masoquismo feminino e moral. As igrejas neopentecostais sustentam a possibilidade de que haveria esse universo paradisíaco na vida daqueles que a elas se moldassem.

As diversas construções discursivas relatadas ao longo deste artigo, que desvelam o universo das promessas religiosas para a vida do crente, insistem que é possível ao sujeito encontrar e ter uma vida de pura felicidade.

No entanto, sabendo-se que não existe cura para a condição estrutural do desamparo humano, a questão inicial que retorna diz respeito ao que põe o sujeito permanentemente a demandar se as promessas gestadas no interior das igrejas neopentecostais não são alcançadas. A esse respeito, deve-se ter em mente o que diz Macedo sobre a fé virtuosa: "Para o cristão, não existe o 'não posso', nem o 'isso é difícil'. Não, não e não! Você pode todas as coisas, se assim crer" (Macedo, 2000, p. 40).

Desse modo, se as bênçãos não se efetivaram na vida do crente, é porque a ele ainda falta a fé vitoriosa, e isso significa a permanente potencialização da demanda pela medida do assujeitar-se ainda um pouco mais, algo que remeta à idéia de que o sujeito ainda não deu tudo de si ou não deu a si mesmo suficientemente ao outro que tem, mas insiste em esconder o objeto da falta.

Pode-se, assim, falar da existência de um princípio de promessa que, em si mesma, sustenta a impossibilidade de cumprimento. E é porque não pode ser cumprida que a promessa potencializa indefinidamente a demanda e marca a condição do processo de subjetivação pelo laço do assujeitamento.

De acordo com Birman (2005), podem-se compreender os processos de reevangelização que são empreendidos pelas religiões no mundo contemporâneo como movimentos de busca de proteção contra o desamparo. Os fundamentalismos se inscrevem nessas promessas de segurança e de verdades inquestionáveis que dariam precisão e consistência à vida.

Os discursos e as práticas fundamentalistas têm crescido expressivamente nas sociedades contemporâneas. Exemplo disso são os diversos estudos feitos sobre os fundamentalismos católico, protestante, islâmico, neoliberal e técnico-científico. Se isso, à primeira vista, parece sustentar um paradoxo dado as conquistas de emancipação humana através das promessas iluministas, não se pode perder de vista, porém, que as transformações ocorridas na atualidade são vividas sob a forma de crises que deixam patente o desencanto com um mundo que parece perder seus fundamentos e substancialidades.

Os processos de subjetivação que são gestados no interior das igrejas neopentecostais parecem aprisionar o sujeito numa lógica de relação intersubjetiva que já lhe é familiar. O que aqui se evidencia é uma aposta numa forma de relação que é balizada pela medida do autocentramento e do apagamento da alteridade do outro, nada muito diferente daquilo que constitui o primado ou a força de sustentação do individualismo das sociedades neoliberais.

É a partir dessa perspectiva, retomando as contribuições iniciais de Deleuze, que se pode estabelecer uma ligação entre a lógica do modo capitalístico de subjetivação e a ética neopentecostal. Parece existir uma simetria entre esses dois campos de forças quanto ao aprisionamento do sujeito numa 
economia subjetiva de autocentramento que é viabilizada às custas do sacrifício dos vínculos com a alteridade. Mesmo que as celebrações religiosas dêem a idéia de uma grande quantidade de pessoas reunidas, pode-se observar que a demanda se dá em função de aspirações individuais, já que os pregadores sustentam discursos que aprisionam os fiéis nesses movimentos individualistas de demanda. Pode-se, assim, postular a inexistência ou a fragilização dos laços sociais em meio às grandes concentrações de pessoas no campo religioso.

A realidade histórica, a partir da qual são processadas as subjetividades regidas pela ética neopentecostal, está remetida ao universo do neoliberalismo. Pode-se ainda dizer que o neopentecostalismo não constitui uma força estruturante de oposição ao neoliberalismo.

Assim, os processos de subjetivação inaugurados pelas igrejas neopentecostais põem em relevo a implicação de diversos campos de forças que se articulam na captura ou na constituição de novas possibilidades de existência humana. Atualmente, o processo midiático tem sido um campo especialmente utilizado nessa direção. A revista Veja, do dia 5 de dezembro de 2007, publicou uma matéria, de Rafael Corrêa, intitulada "Os Templos Espetáculo", na qual salienta que, nos novos templos gigantescos, o culto tem se constituído em um show, e o pastor tem se tornado o astro principal (Corrêa, 2007).

Assim, torna-se importante salientar os campos de forças que estão permanentemente implicados e que promovem a flexão ou a curvatura nos processos de subjetivação.

Inicialmente, deve-se considerar que a demanda de cura explicita o enlaçamento do sujeito diante da produção da promessa. Esse sujeito não representa uma vítima, porquanto a provocação da possibilidade do encontro com um reino humano de pura felicidade - cura - se encontra com sua aspiração por uma vida de inteireza. O sujeito, mais do que ser capturado, na verdade, agarra-se a essa promessa. Ele ouve o que quer ouvir, mesmo que o que lhe seja falado pertença à ordem do impossível. O sujeito, afetado pelas condições de fragilidade em sua corporeidade, imagina poder se livrar de toda forma de sofrimento (primeira dobra).

A demanda de cura, que constitui um campo de força e promove a entrada em novos modos de subjetivação, é potencializada pela confiança de que Deus honrará sua promessa para aqueles que têm uma fé verdadeira. As narrativas e as explicações do universo subjetivo, moldado pelo crivo da fé, dão sustentação a uma racionalidade que indica a compreensão de uma subjetividade privatizada. Trata-se da relação de força que é vergada para constituir uma relação consigo mesmo (segunda dobra).

A ética se apresenta como uma conseqüência imediata e direta para a delimitação dos campos de constituição da subjetividade. Para usufruir de todas as bênçãos possíveis, exige-se que o fiel se molde dentro das lógicas de compreensão dos saberes instituídos nas igrejas neopentecostais. É na terceira dobra, a do saber ou da verdade, que se estabelece a relação da verdade com o ser e do ser com a verdade. Aqui se pode falar de uma subjetivação do saber sob a lógica neopentecostal. É à luz desse saber que se institui a métrica ou o enquadramento do processo de subjetivação do crente. Nesse processo, vive-se o regime do pensamento único, que abole o respeito às diferenças e que descarta a inclusão de qualquer forma de pluralização de possibilidades para a vida humana que contrastem com a vertente religiosa.

A métrica desse processo parece se dar pelo regime do assujeitamento. Se o sujeito 
ainda não usufruiu das bênçãos almejadas, é porque a ele ainda falta uma fé vitoriosa e porque também não se deu plenamente diante das exigências que lhe são feitas. Investimento subjetivo de plena interioridade e afastamento das realidades mundanas parecem constituir dispositivos que atualizam a quarta dobra deleuziana em seu movimento de dupla captura através da cisão entre dentro/fora, indivíduo/sociedade. É aqui que repousa a esperança do sujeito na salvaçãocura. A flexão ou dobra desses campos de força parece desvelar um sujeito imerso no eu ideal que sustenta uma posição imaginária de onipotência. Pode-se aqui falar de um princípio de negação da castração. O sujeito que acredita ter um contrato de parceria ou sociedade com o próprio Deus, no campo de suas demandas de vida, vê-se vocacionado à realização plena de seus desejos.
Desse modo, as demandas observadas no interior das igrejas neopentecostais indicam sujeitos no permanente exercício de busca de uma satisfação pessoal exacerbada. Nessas condições, pode-se falar de um fenômeno religioso desinstitucionalizado, subjetivo e afetivo.

Finalmente, pode-se dizer que a ruptura com uma perspectiva naturalista de compreensão da constituição da subjetividade, que evidencia o sujeito somente a partir de suas características intrapsíquicas, permite a indicação de um espaço de interfaces necessário para a pesquisa sobre os modos de subjetivação. Desvelar o fenômeno religioso na multiplicidade de seus campos de forças, implicado em seus desdobramentos e intensidades com o mundo no qual está inserido, e, sobretudo, como gestor de novos modos de subjetivação, constituiu o objeto de estudo deste artigo. 


\section{Márcio Antônio Gonçalves}

Psicólogo Clínico e Mestrando do Curso de Pós-Graduação em Psicologia Aplicada da Universidade Federal de Uberlândia. Graduação em Teologia pela Universidade Católica de Goiás.

E-mail: marciouber@hotmail.com

\section{Caio César Souza Camargo Próchno *}

Professor Associado - 2 do Instituto de Psicologia e da Pós-Graduação em Psicologia Aplicada da Universidade Federal de Uberlândia. Doutor em Psicologia Social pelo Instituto de Psicologia da USP. Pós-Doutorado pelo Instituto de Filosofia da Universidade de Leipzig (Alemanha).

\section{João Luiz Leitão Paravidini}

Psicólogo e Psicanalista, Professor Adjunto do Instituto de Psicologia e da Pós-Graduação em Psicologia Aplicada da Universidade Federal de Uberlândia. Doutor em Saúde Mental pela Unicamp.

E-mail: paravidini@ufu.br

\section{* Endereço para envio de correspondência:}

Rua Cruzeiro dos Peixotos - 59 - apto. 203 - Bairro: Aparecida

CEP: 38400-608 - Uberlândia - MG

E-mails: c.prochno@uol.com.br

caioprochno@terra.com.br

\section{Referências}

Birman, J. (2005). Mal-estar na atualidade: a psicanálise e as novas formas de subjetivação (5a ed.). Rio de Janeiro: Civilização Brasileira.

Braga de Almeida, J. (1996). Por quê? Que devo fazer? São Paulo: Bompastor.

Corrêa, R. (2007, 5 de dezembro). Os templos espetáculo. Veja, ano $40(48), 126-132$.

Deleuze, G. (1986). Foucault. São Paulo: Brasiliense.

Duarte Jr., J. B. (1997). Itinerário de uma crise: a modernidade. Curitiba: UFPR.

Ferreira Neto, J. L. (2004). Processos de subjetivação e novos arranjos urbanos. Recuperado em 13 de outubro de 2007, de http://www.uff.br/ichf/publicacoes/revista_psicologia_acervo. $\mathrm{htm}$

Forbes, I. (2004). O sofrimento na cultura atual: hedonismo versus alteridade. In C. A. Peixoto Jr., Formas de subjetivação. Rio de Janeiro: Contra Capa Livraria.

Foucault, M. (1984). História da sexualidade 2: o uso dos prazeres. Rio de Janeiro: Graal.

Lara, T. (1988). Caminhos da razão no Ocidente: a filosofia ocidental, do Renascimento aos nossos dias. Petrópolis, RJ: Vozes.
Linhares, J. (2005). O homem abençoado. Belo Horizonte: Getsêmani.

Lipovetsky, G. (2004). Os tempos hipermodernos. São Paulo: Barcarolla.

Macedo, E. (2000). Vida com abundância. Rio de Janeiro: Universal.

Macedo, E. (2005). O despertar da fé. Rio de Janeiro: Universal.

Mariano, R. (2005). Neopentecostais: sociologia do novo pentecostalismo no Brasil. São Paulo: Loyola.

Marinho, F. (2001). As batalhas da vida. Campinas, SP: D'Sena.

Neves da Silva, R. (2004). A dobra deleuziana: políticas de subjetivação. Recuperado em 13 de outubro de 2007, de http://www.uff.br/ichf/publicacoes/revista_psicologia_acervo. $\mathrm{htm}$

Pereira, C., \& Linhares, J. (2006, 12 de julho). Os novos pastores. Veja, ano 39(27), 76-85.

Saragoça, Y. C. B. (2004). Evangelizando homens de negócios: o pentecostalismo e o empresariado. Dissertação de Mestrado em Ciências Sociais, Universidade Federal de São Carlos, São Carlos, SP.

Soares, R. R. (2004). Como tomar posse da benção. Rio de Janeiro: Graça. 